\title{
Minimizing Crop Damage Through Understanding Relationships Between Pyrethrum Phenology and Ray Blight Disease Severity
}

Sarah J. Pethybridge, The New Zealand Institute for Plant \& Food Research, Private Bag 4704, Christchurch, New Zealand; David H. Gent, United States Department of Agriculture-Agricultural Research Services, Forage Seed and Cereal Research Unit and Oregon State University Department of Botany and Plant Pathology, Corvallis 97331; Tim Groom, Botanical Resources Australia-Agricultural Services Pty. Ltd., Australia; and Frank S. Hay, Tasmanian Institute of Agriculture, University of Tasmania, Burnie, Tasmania 7320, Australia

\begin{abstract}
Pethybridge, S. J., Gent, D. H., Groom, T., and Hay, F. S. 2013. Minimizing crop damage through understanding relationships between pyrethrum phenology and ray blight disease severity. Plant Dis. 97:1431-1437.

The most damaging foliar disease of pyrethrum in Australia is ray blight caused by Stagonosporopsis tanaceti. The probability of growers incurring economic losses caused by this disease has been substantially reduced by the implementation of a prophylactically applied spring fungicide program. This has been traditionally initiated when $50 \%$ of the stems have reached between 5 and $10 \mathrm{~cm}$ in height. Data collected on the emergence of stems from semidormant plants over late winter from 27 fields across northern Tasmania from 2009 to 2011 were used to develop a degree-day model to assist with initiation of the fungicide program. Temporal changes in cumulative proportion of plants with elongated stems were well described by a logistic growth model $\left(R^{2} \geq\right.$ 0.97 across all fields). These models were used to calculate the number of days until $50 \%$ of the sampling units had at least one elongated stem for the calculation of simple degree-days, assuming a nominal biofix date of the austral winter solstice. The median date for $50 \%$ stem elongation was estimated as 30 August in these data sets. Mean error and

root mean square error of degree-day models were minimized when a base of $0^{\circ} \mathrm{C}$ was selected. Mixed-model analysis found prediction errors to be significantly affected by geographic region, requiring the use of scalar correction factors for specific production regions. In the Western region, $50 \%$ stem emergence was predicted at 590.3 degree-days (mean prediction error $=0.7$ days), compared with 644.6 (mean prediction error $=7.7$ days) in the Coastal region and 684.7 (mean prediction error $=0.7$ days) degree-days in the Inland region. The importance of fungicide timing for initiation of the spring disease management program in minimizing losses (expressed as percent disease control in October) was also quantified. This relationship was best explained by a split-line regression with a significant break-point of 513.8 degree-days, which corresponded to $10.7 \%$ of sampling units with elongated stems. Overall, this research indicated that disease management may be improved by applying the first fungicide of the program substantially earlier in phenological development of the stems than currently recommended.
\end{abstract}

The timing of initiation of control measures is a significant aspect of efficient management of plant disease epidemics. The first coincident occurrence of pathogen inoculum, environmental conditions favorable for pathogen dispersal and infection, and presence of susceptible host tissue has been termed the "critical period" (34). Implementation of tactics such as a fungicide application at or just before the critical period may reduce or prevent a primary infection event. Control measures initiated before a critical period may be unnecessary and wasteful, whereas measures applied too late can potentially result in diminished disease management efficacy. Management efforts, whether they be tactical or strategic in nature, targeted to coincide with the critical period may have the most benefit in reducing overall epidemic severity (11).

Pyrethrum (Tanacetum cinerariifolium (Trevir.) Sch. Bip.) is grown for the extraction of pyrethrins, which are contained within the achenes of the flowers, for the manufacture of a range of mostly household insecticidal products (4). At least $60 \%$ of the global market for pyrethrins is supplied by the Australian industry, for which a production area of approximately 3,000 ha is centered in

Corresponding author: S. J. Pethybridge,

E-mail: Sarah.Pethybridge@ @lantandfood.co.nz

Mention of a trademark, proprietary product, or vendor does not constitute a guarantee or warranty of the product by the United States Department of Agriculture and does not imply its approval to the exclusion of the products or vendors that may also be suitable.

Accepted for publication 3 February 2013.

http://dx.doi.org/10.1094/PDIS-11-12-1102-RE

(C) 2013 The American Phytopathological Society northern Tasmania and the Ballarat region of Victoria. In Australia, pyrethrum production is ideally perennial and fields are planted in spring (late July to October). Plants then remain in a semidormant rosette form for a further 12 months prior to the development of flowering stems in the subsequent spring, which form the flowers that are mechanically harvested in late December and January thereafter. Following harvest, plants regrow during the autumn period, become semidormant over winter, and again develop stems and flowers each spring for up to four to five annual harvests (4).

In the case of ray blight, caused by Stagonosporopsis tanaceti (syn. Phoma ligulicola var. inoxydabilis) $(1,26,32)$, disease management is highly dependent on fungicide applications beginning in spring that are intended to protect developing flowering stems. Previous studies have suggested that young stems are the phenological stage most susceptible to infection by $S$. tanaceti $(13,14,16,20)$. Diseased stems developing in early spring can be the most deleterious to the yield potential of the crop, with early chlorotic symptoms closely followed by generalized necrosis and distortion $(13,18)$. A spring fungicide program was introduced in 2002 in response to severe losses incurred from annual epidemics (20). In replicated trials conducted in 2002 and 2003, fungicide applications resulted in a doubling of the number of flowers produced, leading to significant increases in pyrethrin yield (24). Moreover, across 96 fields in two subsequent years, average increases in pyrethrin yield of $79.5 \%$ were achieved as a result of the spring fungicide program (24). A range of fungicide chemistries have been used within the program to date, of which some have developed resistance and, hence, have been discarded from the program (9). Currently, the program is dependent upon the succinate dehydrogenase inhibitor boscalid, which provides effective control of ray blight (18) as well as Sclerotinia crown rot caused by Sclerotinia minor and S. sclerotiorum $(18,22)$. 
Interestingly, the severity of ray blight epidemics has been clearly linked to several risk factors, including seedborne inoculum $(16,22)$; environmental conditions during autumn and winter, which contribute directly to the overwintering success of the pathogen and indirectly to defoliation severity in spring (16); and sitespecific risk factors such as temperature and rainfall $(15,17)$. The importance of seedborne inoculum is further emphasized because of the absence of evidence for the teleomorph, Didymella ligulicola $(1-3,5,14)$.

Degree-days relate biological events to time duration at various temperatures $(6,28,33)$. Various methods for estimating threshold temperatures directly from field observations have been utilized (27,29-31,33). A common approach involves calculating a mean thermal time to a temperature-dependent event using various combinations of base or upper temperature thresholds and recursively assessing prediction errors. The combination of base and upper temperature thresholds that minimizes a measure of variability or prediction error is then selected as the final model from among the competing models.

The development of pyrethrum stems in spring following the winter semidormancy period is also likely to be driven by thermal time. Currently, the spring fungicide program is initiated when $50 \%$ of stems within the field reach 5 to $10 \mathrm{~cm}$ in height, which is assessed informally (18). However, there is little biological basis for this threshold and reduced disease losses may be possible by quantifying this threshold to accurately time the initiation of the first fungicide application with development of susceptible stems in spring. The primary objective of this research was to develop a degree-day model to predict stem elongation as an aid to improve timing of the first fungicide application used within the spring fungicide program. A complementary objective was to quantify the importance of the first fungicide application on minimizing losses from this disease.

\section{Materials and Methods}

Degree-day model development for stem elongation. Model development fields. Data on the emergence of pyrethrum stems from semidormancy was obtained from 8 commercial fields in 2009 and 2010 and 11 fields in 2011. All fields were approaching first-harvest and were randomly selected to represent the spectrum of production regions in northern Tasmania (termed Western, Coastal, and Inland in this article). Each field was grown under standard production practices, which included irrigation, fertilizer, fungicide, and herbicide applications. Within each field, a geospatially referenced area was established in which monitoring for pyrethrum growth was conducted. At each location, a $1-\mathrm{m}^{2}$ quadrat was placed on the ground and separated evenly into smaller $20-\mathrm{cm}^{2}$ grids. In 2009, four quadrats were placed immediately adjacent to each other, providing 80 smaller observation grids. In the latter 2 years of the study, five quadrats were used within each field, totaling 100 grids per field at each observation time period. Within each $20-\mathrm{cm}^{2}$ grid, the presence or absence of at least one stem $>5 \mathrm{~cm}$ in height was noted at each assessment time. Grids without any plants were recorded as missing data. Grids were assessed every 2 to 3 days until all grids that had plants possessed stems $>5 \mathrm{~cm}$ in height. The intensity of plant growth assessments among fields varied between 22 and 28, 21 and 24, and 15 and 25 events in 2009, 2010, and 2011, respectively.

Progress curves describing the cumulative proportion of plants with elongated stems over time were constructed for each field ("data set") and a three-parameter logistic growth model was fitted to each in the form of:

$$
y=\frac{a}{1+\left(x / x_{0}\right)^{b}}
$$

where $y$ is the proportional of plants with elongated stem, $x_{0}$ is the date of the first observation, $x$ is the number of days since the first observation, $a$ is an asymptote parameter, and $b$ is a rate parameter. Models were fit using the NLIN procedure in SAS (version 9.2;
SAS Institute), and goodness of fit assessed based on $R^{2}$ value, standard error of the parameter estimates, and residual diagnostics (10). From each of the progress curves, the number of days elapsed to when $50 \%$ of plants had at least one elongated stem was estimated by rearranging equation 1 to solve for $x$. This date was used in subsequent calculations to derive the base temperature for degree-day models because this point was considered to be less sensitive to extreme values than other days such as date of the first stem elongation or all stems elongated.

Weather data. The centroid of each pyrethrum field was recorded with a handheld GPS unit (GPS eTrex Vista HCx; Garmin International Inc.) and used as a geospatial reference for obtaining interpolated site-specific daily temperature data from the Queensland Department of Natural Resources and Mines Data Drill algorithm at a $5-\mathrm{km}^{2}$ spatial resolution $(7,8)$. Errors associated with the use of interpolated compared with on-site temperature data in northern Tasmania have been reported previously (15).

Degree-days. Simple degree-days up to the day of $50 \%$ stem elongation were determined using base temperatures in $1{ }^{\circ} \mathrm{C}$ increments between 0 and $25^{\circ} \mathrm{C}$. Data reported herein are for models with base temperatures up to $13^{\circ} \mathrm{C}$. Simple degree-days were calculated according to Ring et al. (29) as (daily maximum air temperature + daily minimum air temperature) $/ 2$ - base temperature). If (daily maximum air temperature + daily minimum air temperature) $/ 2<$ base temperature, then (daily maximum air temperature + daily minimum air temperature) $/ 2$ was set to the base temperature (method 1 as described by McMaster and Wilhelm [12]). Upper temperature thresholds were not considered because field measurements of stem elongation occurred during later winter and early spring, when super-optimal temperature would be highly unlikely. The austral winter solstice (21 June in non-leap years) was selected as the nominal biofix date based on preliminary evaluation of earlier biofix dates.

For each data set, daily degree-day values were summed from the biofix to the date of $50 \%$ stem elongation for each of the various base temperatures. The mean cumulative degree-days among the 27 data sets were then considered the threshold to $50 \%$ stem elongation and the standard deviation about the mean was calculated. The mean error and root mean square error in calendar days was calculated iteratively for each competing base temperaturethreshold degree-day model. To do this for a given model, each data set was evaluated to determine when the threshold degreedays (for a given base temperature) was attained. The difference in days between actual date of $50 \%$ stem elongation and the date when the degree-day threshold was attained was recorded and used to calculate mean error and root mean square error over all 27 data sets. The base temperature that minimized mean error and root mean square error was deemed the most skillful and utilized in subsequent analyses. A full description of the approach is provided by Snyder et al. (31).

Inspection of prediction errors indicated a systematic bias of stem elongation dependent on geographic region of the field. To correct for these regional effects, a mixed-model analysis was conducted using the MIXED procedure in SAS. The observed degreedays with base $0^{\circ} \mathrm{C}$ (selected based on characteristics described below) was modeled as dependent on the fixed effect of geographic region (classified as Western, Coastal, or Inland) and random effect of field within regions. Differences in least square means estimates of each region were compared by $t$ tests in SAS.

Modeling the effects of degree-days on stem elongation. Conceptually, stem elongation in relationship to degree-day accumulation at a given field can be considered to be field specific, with a random deviation from some population average. In such instances, random coefficient analysis provides a framework to derive population-level parameter estimates and assess heterogeneity of the relationship between response and predictor variables (10). Once a reasonable base temperature for a degree-day model was obtained, a logistic model of stem growth in relationship to degree-days was fitted over all data sets, considering each field a random factor in a nonlinear mixed model. Stem growth measurements and corre- 
sponding accumulated degree-days (base $0^{\circ} \mathrm{C}$ ) for all fields were fitted to a random coefficient version of equation 1 . Considering each field a random factor allowed each field to have its own subject-specific parameter estimates, which can enter the model nonlinearly. The model for the $j$ th stem growth observation at the $i$ th field is given by:

$$
y_{i j}=\frac{a+u_{i 1}}{1+\left[x_{i j} /\left(x_{0}+u_{i 2}\right)\right]^{b}}+e_{i j}
$$

The parameters were as described above for equation 1. Parameters $u_{i 1}$ and $u_{i 2}$ are random effect parameters that allowed each field to have its own field-specific asymptote and time-scale parameters. For this analysis, the upper asymptote parameter $a$ was set to $100 \%$ stem elongation for biological relevance and to aid in model convergence. The random coefficient $u_{i 2}$ was modeled to have a normal distribution with variance $\sigma_{2}$. Appropriateness of model fit was assessed by inspection of residual plots and observed versus measured field-specific estimates of stem elongation, relative gradient convergence, and value of the convergence criteria. A full description of the analysis approach can be found in Littell et al. (10).

Relationship between first fungicide application timing and ray blight severity. The association between timing of the first fungicide and disease severity was quantified using fungicide effi-
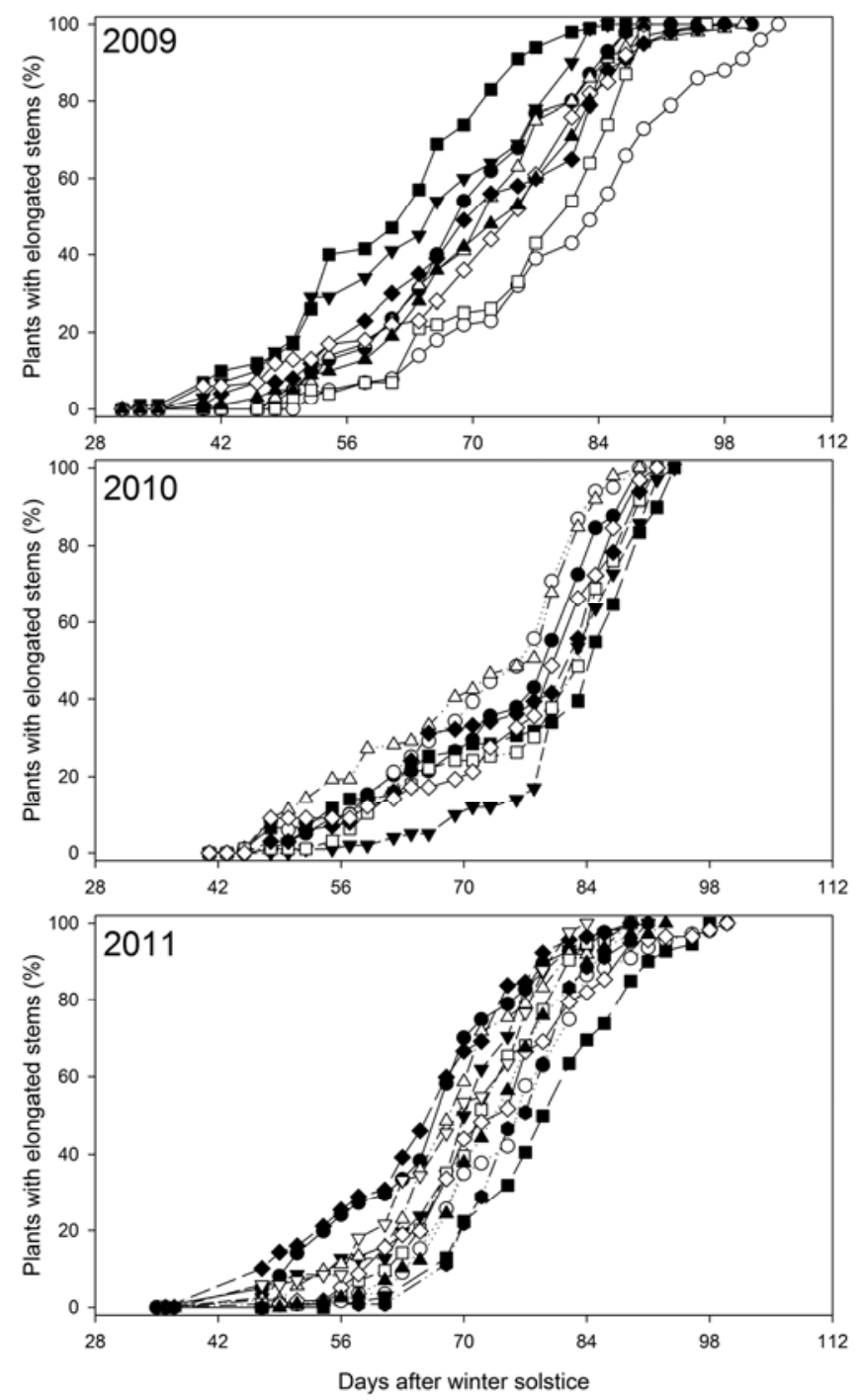

Fig. 1. Percentage of pyrethrum plants with elongated stems in relationship to days after the austral winter solstice. Data are from 27 pyrethrum fields in Tasmania, Australia assessed for stem growth during 2009 to 2011. Symbols indicate different fields within each year. cacy information in 44 fields from 2003 to 2005, across all three geographic production regions defined by the degree-day model development analysis. In each field, two plots $(10 \mathrm{~m}$ long by $24 \mathrm{~m}$ wide) were established. The first plot received the industry-recommended fungicide protocol (24) and was applied by individual growers using on-farm spray equipment. Fungicides were applied using a volume of 300 liters/ha at a pressure of approximately 200 $\mathrm{kPa}$. The second plot did not receive any fungicide treatments. Plots were separated by an area of $5 \mathrm{~m}$ consisting of pyrethrum which did not receive any fungicides. Disease intensity in both plots in all fields was assessed between 7 and 12 October 2003, 6 and 11 October 2004, and 8 and 10 October 2005 by measuring defoliation severity in 60 systematically selected flowering stems along three linear transects covering the entire width of the plots. Stems were destructively sampled by breaking as close as possible to the soil line and transported to the laboratory for measurements within $48 \mathrm{~h}$. Defoliation severity was defined as the height at which leaves were either completely necrotic or abscised compared with overall stem length and expressed as a percentage (14).

Percent disease control was calculated for each field as 100(1 $y_{\mathrm{t}} / y_{\mathrm{c}}$ ), where $y_{\mathrm{t}}$ and $y_{\mathrm{c}}$ were ray blight defoliation severity in the fungicide-treated plot and nontreated control plots, respectively. Percent disease control was regressed on the date of the first fungicide application, expressed as the summation of degree-days base $0^{\circ} \mathrm{C}$, by linear and split-line regression models. Dates of fungicide applications were obtained from grower production records.

\section{Results}

Degree-day model development for stem elongation. Stem elongation across all fields increased in a sigmoidal pattern over time (Fig. 1). Among fields, the date of first elongated stem was observed on assessments conducted from 24 July to 7 August. Stem elongation was observed on all plants by 13 September to 3 October, and was found to be highly field dependent.

Logistic growth models were fit successfully to data from each field and provided an adequate description of stem elongation, with $R^{2}$ values no less than 0.97 for any field. Based on the parameter estimates from each field, the date of $50 \%$ stem elongation was estimated and was normally distributed among fields with a median date (rounded up) of 30 August (Fig. 2).

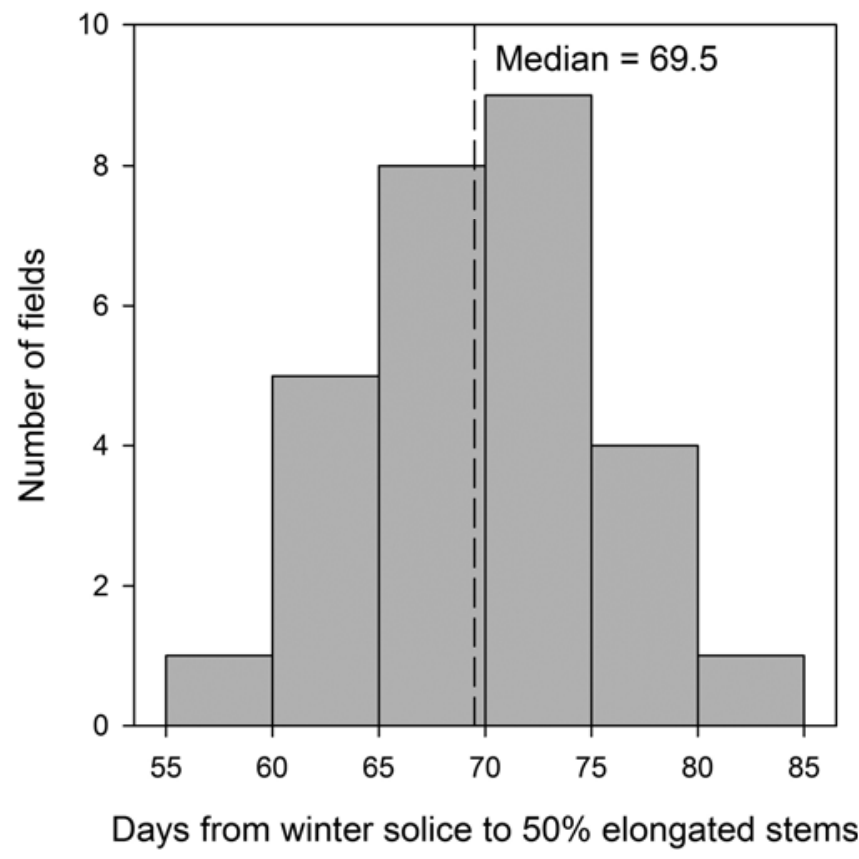

Fig. 2. Distribution of number of days from the austral winter solstice to elongation of stems on pyrethrum plants among 27 fields in Tasmania, Australia. The 50\% stem elongation date was estimated from the data in Figure 1 by fitting three parameter logistic growth models to data from each field separately. 


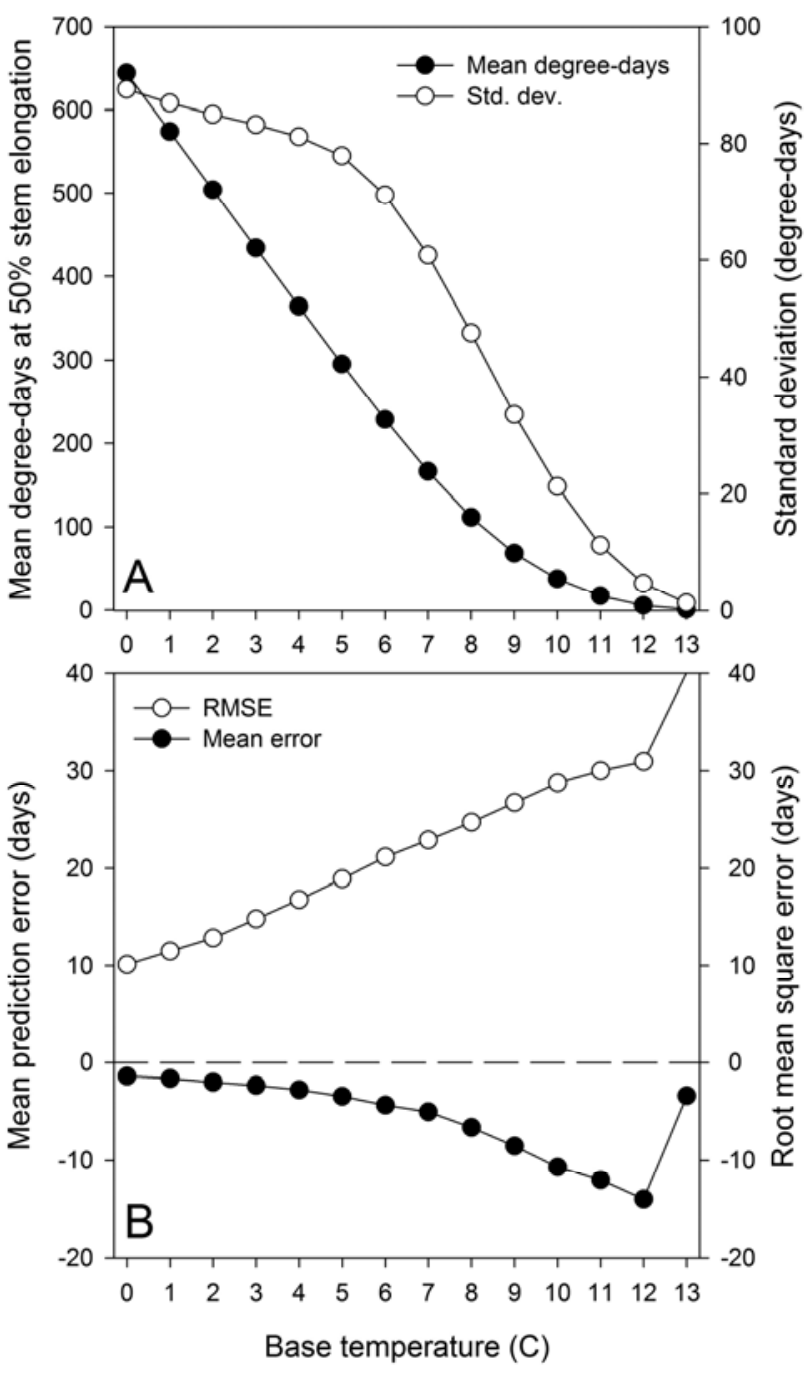

Fig. 3. Characteristics and errors associated with degree-day models to predict pyrethrum stem elongation utilizing varying base temperatures. A, Mean and standard deviation (Std. dev.) of degree-days when $50 \%$ of plants have elongated stems. B, Mean prediction errors and root mean square error (RMSE) based on calendar days for the competing models. Data are from 27 pyrethrum fields in Tasmania, Australia assessed for stem growth during 2009 to 2011.
The mean cumulative degree-days to the day of $50 \%$ stem elongation decreased from 644.3 with base $0^{\circ} \mathrm{C}$ to approximately 0 at base $13^{\circ} \mathrm{C}$ (Fig. 3A). Standard deviation of the models was greatest with base $0^{\circ} \mathrm{C}$ and decreased to approximately 0 at base $13^{\circ} \mathrm{C}$ because the mean was systemically related to the variance. However, mean error and root mean square error were smallest with base $0^{\circ} \mathrm{C}$. (Fig. 3B). Therefore, a base of $0^{\circ} \mathrm{C}$ was selected for use in subsequent analyses.

Prediction errors (expressed in days) were not random but related to geographic region (Fig. 4). A mixed-model analysis considering fields within region as random factors indicated that $50 \%$ stem emergence occurred at 590.3 degree-days in fields in the Western region, 644.6 degree-days in the Coastal region, and 684.7 degree-days in Inland production regions (model significant at $P=$ $0.0504)$. Stem elongation in relation to degree-day accumulation is depicted in Figure 5. Mean degree-days at 50\% stem elongation were significantly less in the Western versus Inland regions $(P=$ 0.0154). Multiplication of 590.3 degree-days, the mean for the Western region, by scalar correction factors of 1.092 for the Coastal fields and 1.16 for fields in the Inland region reduced systematic prediction errors (Fig. 4). Overall prediction errors were -2.4 days with the mixed-effect model and -1.4 days for the fixedeffect model. However, standard deviation in degree-days with the mixed-effect model was reduced to 79.2 and root mean square error in days was reduced to 9.2 .

Modeling the effects of degree-days on stem elongation. A mixed-effect logistic model could be fit to data sets from all fields, as indicated by residual diagnostics and small $(P<0.000001)$ final gradient values for all parameter estimates. The population level parameter estimates were $a=640.54$ (standard error 15.49) and $b=$ -9.558 (standard error 0.168$)$, both of which were significant $(P<$ 0.0001 ). The variance component for the random coefficient $u_{2}$ (for parameter $a$ ) was 6675.21 (standard error $=1792.85$ ) and significant $(P=0.0009)$, indicating that the random effects for the beginning of stem emergence varied among fields (Fig. 6). Field-specific effects of $u_{2}$ were -203.4 to 124.2 , with a median of 16.9 and standard deviation of 82.95. The population-level parameter estimates allowed calculation of mean percent stem elongation as a function of degree-days.

Relationship between first fungicide application timing and ray blight severity. Among the 44 fields, percent control of ray blight was related to the timing of the first fungicide application when expressed as cumulative degree-days from the biofix (Fig. 7). A linear relationship between percent disease control and first

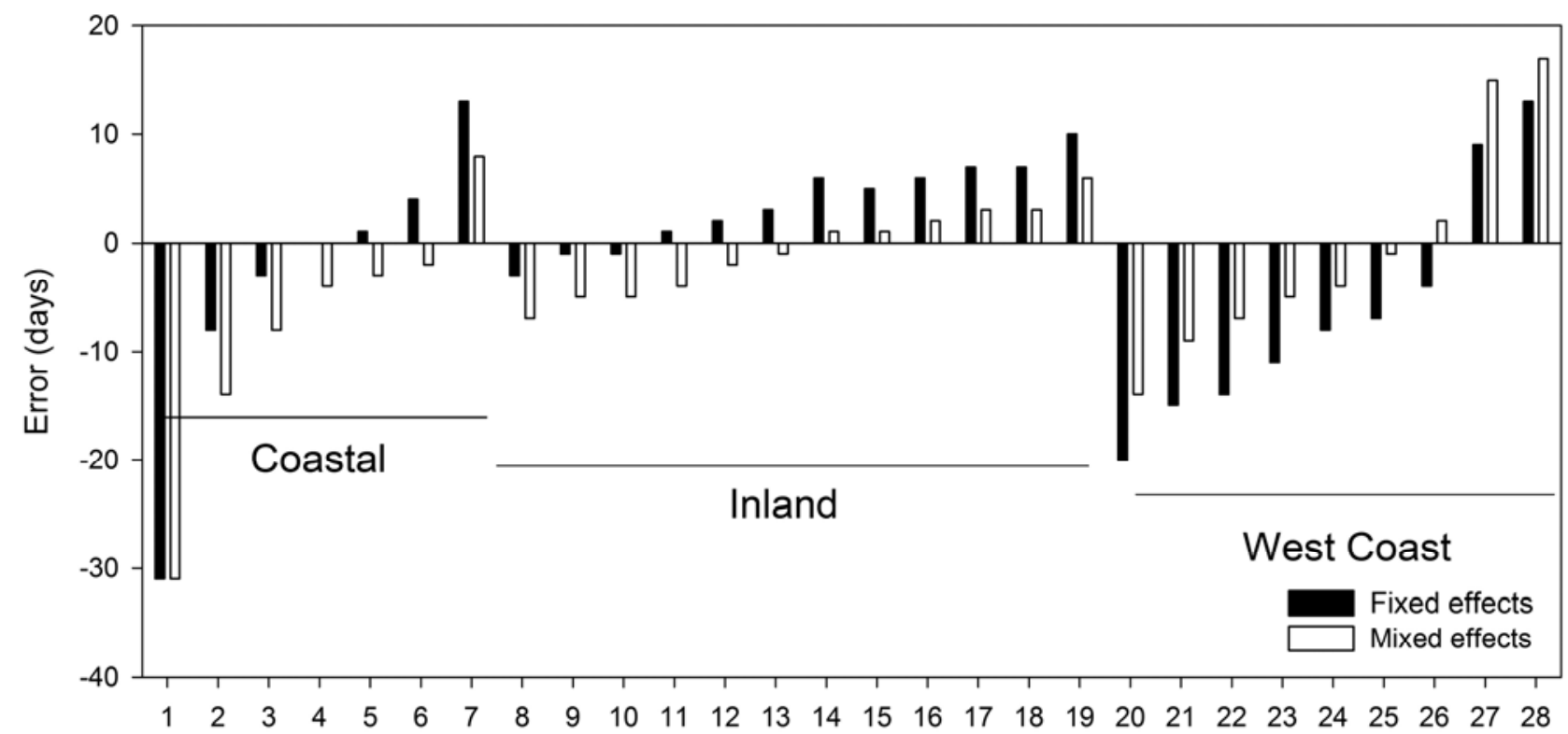

Fig. 4. Distribution of prediction errors of degree-day models (base $0^{\circ} \mathrm{C}$ ) for pyrethrum stem elongation. Models were derived assuming a fixed effect of fields (fixed effects) or a fixed effect of geographic region (Coastal, Inland, and West Coast) and random fields nested within geographic regions (mixed effects). 
fungicide application timing was significant $\left(R^{2}=0.40 ; P<\right.$ $0.0001)$, and explained by:

$\%$ disease control $=$

$121.8-0.134 \times($ degree-days at first fungicide application $)$

The distribution of the data suggested a threshold-type response, where percent disease control decreased linearly with later timings of the first fungicide application. A split-line regression was fitted to the data $\left(R^{2}=0.45 ; P<0.0001\right)$, and a significant break-point $(P$ $<0.0001)$ was found at 513.8 degree-days. The regression model was $\%$ disease control $=(61.173 \times(513.8-$ degree-days $)+61.909$ $\times$ (degree-days -348.75$) / 165.05$ when degree-days were less than 513.8 ; and $61.909 \times(760-$ degree-days $)+12.693 \times($ degree-days - 513.8)/247.238 otherwise. Based on the population average estimates of stem elongation (Fig. 6), the break-point of 513.8 degree-days corresponded to $10.7 \%$ of plants with elongated stems.

\section{Discussion}

This study has demonstrated that a change in paradigm for initiation of the disease management program is needed. The most appropriate phenological stage for fungicide program initiation can
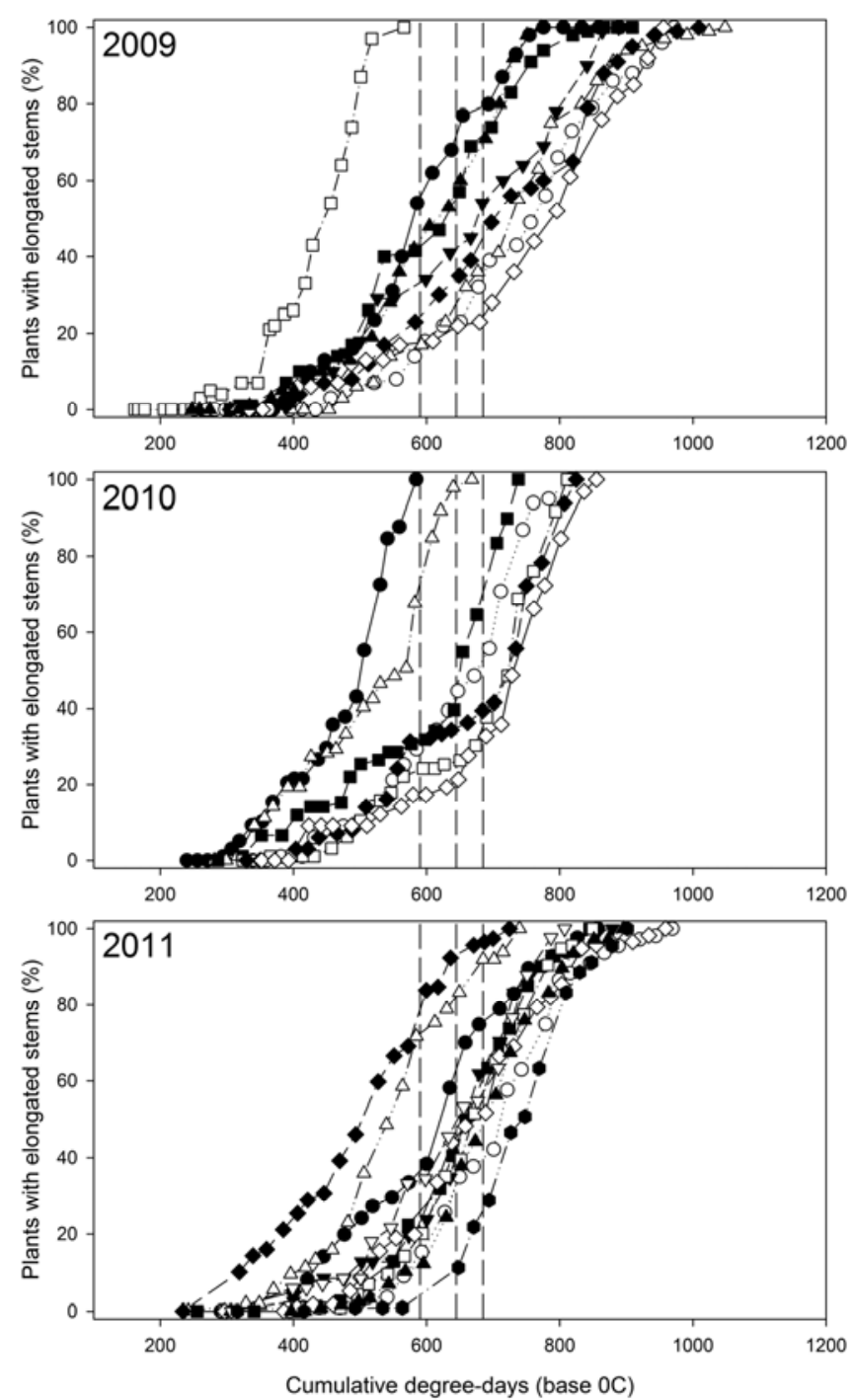

Fig. 5. Percentage of pyrethrum plants with elongated stems in relationship to cumulative degree-days (base $0^{\circ} \mathrm{C}$ ) beginning at the austral winter solstice. Dashed lines are population averages for degree-day thresholds for $50 \%$ stem elongation in three production regions (Western, Coastal, and Inland). Thresholds are 590.3, 644.6, and 684.7 degree-days for Western, Coastal, and Inland regions, respectively. Data are from 27 commercial pyrethrum fields in Tasmania, Australia assessed for growth during 2009 to 2011. Symbols indicate different fields within each year. be modeled effectively by degree-days using the winter solstice as a biofix date and a base temperature of $0^{\circ} \mathrm{C}$, including a correction factor for geographic region. Fungicide applications made after the accumulation of 514 degree-days, corresponding to approximately $10 \%$ of plants with at least one emerged stem, tended to result in relatively poor disease management when expressed as percent disease control compared with nontreated plants. This timing is substantially earlier than current commercial practice. Considering depiction of the temporal progress of ray blight epidemics in the early spring disease period as polycyclic (14), delays to initiation of the program are likely to contribute to suboptimal disease control in the field $(18,19,21,23)$. Practically, delays to fungicide application are incurred by irregular field scouting, adverse weather conditions, and, in some cases, availability of agrichemicals. Initiating the program prior to stem elongation is likely to also minimize these practical concerns and crop loss by reducing the rate of epidemic progress (11).

There was considerable variability in when pyrethrum stems began elongation among both regions and fields within regions. A mixed-modeling approach identified significant differences in stem elongation between production regions in the Western, Coastal, and Inland production areas. The date of 50\% stem elongation varied by 94 degree-days among these regions. This variability may be due to differences in production practices such as generally earlier planting dates in the Western region, followed by the Coastal and Inland regions. Precipitation also tends to be greater in the Western production region. How these and other factors precisely influence initial stem elongation is unclear. However, the rate of stem elongation among fields and regions was similar when expressed relative to degree-days, and the primary source of variability appears to be when initial stem elongation commenced (Figs. 5 and 6), which is supported by the random coefficient analysis.

Previous research on ray blight found that overwintering inoculum density is closely associated with epidemic severity in spring (16). The current study supports this finding, in that fungicide applications made earlier than currently recommended are associated with the most effective control of ray blight. This may be re-
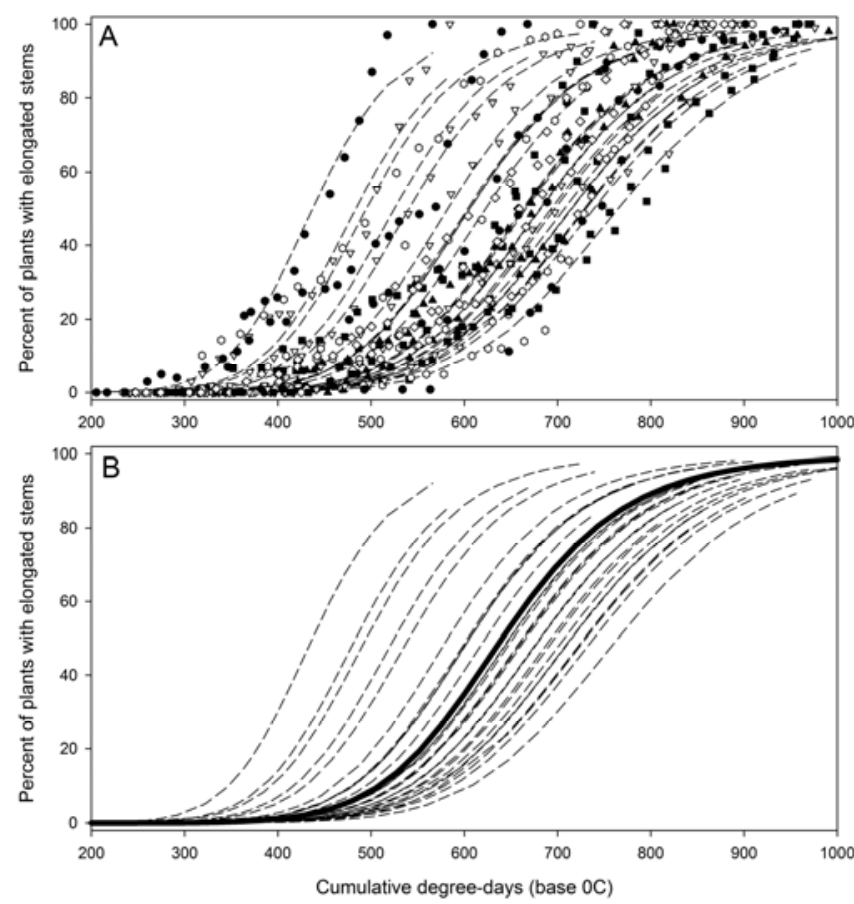

Fig. 6. A, Field-specific pyrethrum stem emergence in relationship to cumulative degree-days from the winter solstice in 27 fields in Tasmania, Australia. Each field is represented by a different symbol. B, Population average prediction of stem emergence based on a nonlinear mixed-effect model. Dashed lines are fieldspecific empirical estimates and the heavy solid line is the population-average prediction of a two-parameter logistic growth model. 
lated to suppression of overwintering inoculum. Although there appears to be a threshold response where fungicide efficacy diminishes, the optimal timing of the first fungicide application may be earlier than the range of dates available in this study, which varied by approximately 400 degree-days (Fig. 7). Research is ongoing to quantify the value of fungicide applications made during autumn and early winter to reduce overwintering of Stagonosporopsis tanaceti and, in turn, epidemic development during spring.

The dominant source of inoculum for ray blight of pyrethrum has been suggested as infested seed $(16,22)$. Low diversity within the pathogen population (25), minimal transfer between isolated fields (15), and the absence of direct observation of the teleomorph stage (14) are also suggestive of the dominant role of a localized, homogeneous primary inoculum source. This situation offers a unique opportunity for effective intervention of the disease cycle and perpetuation of any fungicide-resistant isolates which may develop. This may occur through the implementation of a nonchemical-based seed treatment, such as hot water, for the establishment of planting material of seed crops at isolated locations. The implementation of a degree-day phenological model for timing the first fungicide application also assumes that the direct effect of overwintering inoculum is, for practical purposes, equal between fields.

Therefore, despite the optimization of the fungicide-based management program by manipulating first application with phenological stage, the continued reliance upon fungicides may not be sustainable. This is likely to be magnified from the limited availability of fungicides in different resistance groups. This necessitates the use of the same chemistries on seed and commercial fields, which is highly problematic in a perennial crop requiring multiple fungicide applications annually. For example, in the 18-month period between planting and first harvest alone, fields may receive up to 12 applications of fungicides from, on average, four resistance groups. Further research should focus on reducing the reliance of the disease-management program on fungicides by investigating the role of seedborne inoculum or the economics of controlling overwintering inoculum and disease severity prior to early spring, when the early initiation of optimal disease management is a criti-

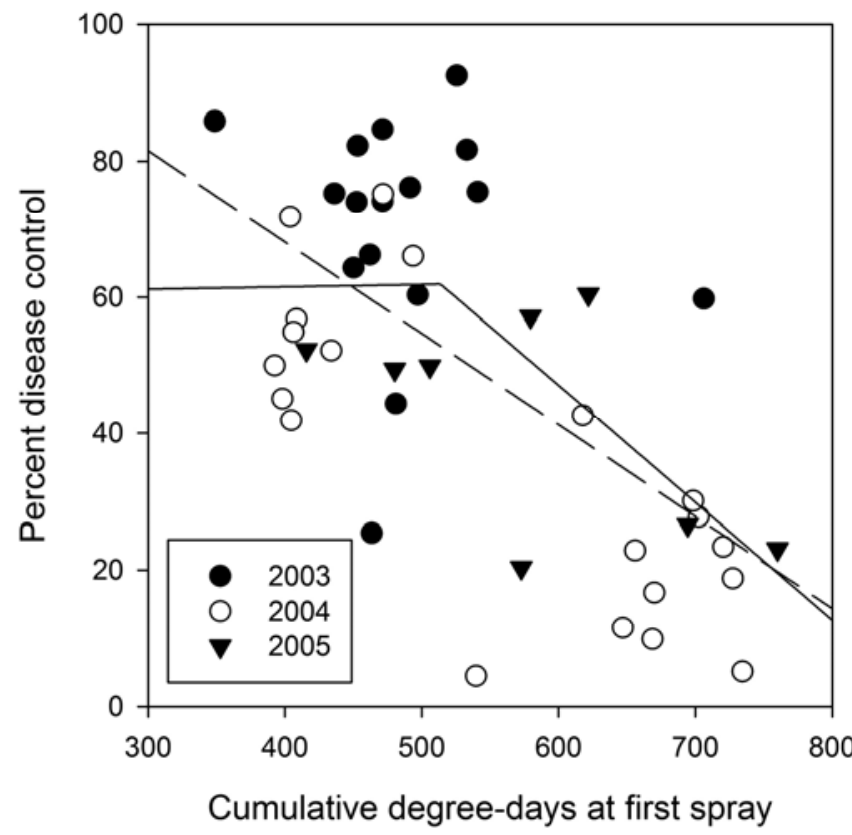

Fig. 7. Relative control of ray blight (caused by Stagonosporopsis tanaceti) in pyrethrum relative to the timing of the first fungicide application in 44 commercial pyrethrum fields in Tasmania, Australia. Relative disease control was calculated from assessments of defoliation severity in nontreated and fungicide-treated plots in each field. The dashed line is the fit of a linear regression $\left(R^{2}=0.39 ; P<0.0001\right)$ and the solid line is a split-line regression $\left(R^{2}=0.45 ; P<0.0001\right)$. The breakpoint in the split-line regression occurs at 514 degree-days. cal control period for preventing crop loss (34). Until such alternatives are available, well-timed fungicide applications will continue to be essential to successfully manage ray blight. The degree-day models developed in this research will aid these efforts.

\section{Acknowledgments}

We thank the financial supporters of our programs, including Botanical Resources Australia-Agricultural Services Pty. Ltd., the Pyrethrum Growers' Research and Development Committee, matched funding from the Australian Commonwealth Government through project PY09002 facilitated by Horticulture Australia Ltd., and the United States Department of Agriculture-Agricultural Research Service CRIS 5358-21000-045-00; and L. Hingston and L. Head for technical assistance.

\section{Literature Cited}

1. Aveskamp, M. M., de Gruyter, J., Woudenberg, J. H. C., Verkley, G. J. M., and Crous, P. W. 2010. Highlights of the Didymellaceae: a polyphasic approach to characterise Phoma and related Pleosporalean genera. Stud. Mycol. 65:1-60.

2. Baker, K. F., Dimock, A. W., and Davis, L. H. 1949. Life history and control of the Ascochyta ray blight of chrysanthemum. Phytopathology 39:789805.

3. Baker, K. F., Dimock, A. W., and Davis, L. H. 1961. Cause and prevention of the rapid spread of the Ascochyta disease of chrysanthemum. Phytopathology 51:96-101.

4. Bhat, B. K., and Menary, R. C. 1984. Pyrethrum production in Australia: its past and present potential. J. Aust. Inst. Agric. Sci. 189-192.

5. Fox, R. T. V. 1998. Chrysanthemum ray blight. Mycologist 12:135-136.

6. Hagstrum, D. W., and Milliken, G. A. 1991. Modeling differences in insect developmental times between constant and fluctuating temperatures. Ann. Entomol. Soc. Am. 84:369-379.

7. Hutchinson, M. F. 1995. Interpolating mean rainfall using thin plate smoothing splines. Int. J. Geographic. Inf. Syst. 9:385-403.

8. Jeffrey, S. J., Carter, J. O., Moodie, K. M., and Beswick, A. R. 2001. Using spatial interpolation to construct a comprehensive archive of Australian climate data. Environ. Model. Softw. 16/4:309-330.

9. Jones, S. J., Pethybridge, S. J., Hay, F. S., Groom, T., and Wilson, C. R 2007. Baseline sensitivity of Australian Phoma ligulicola isolates from pyrethrum to azoxystrobin and difenoconazole. J. Phytopathol. 155:377380 .

10. Littell, R. C., Milliken, G. A., Stroup, W. W., Wolfinger, R. D., and Schabenberger, O. 2006. SAS for Mixed Models. SAS Institute Inc., Cary, NC.

11. Madden, L. V., Hughes, G., and van den Bosch, F. 2007. The Study of Plant Disease Epidemics. American Phytopathological Society, St. Paul, MN.

12. McMaster, G. S., and Wilhelm, W. W. 1997. Growing degree-days: one equation, two interpretations. Agric. For. Meteorol. 87:291-300

13. Pethybridge, S. J., Esker, P. D., Dixon, P., Hay, F. S., Groom, T., Wilson, C. R., and Nutter, F. W., Jr. 2007. Quantifying loss caused by ray blight disease in Tasmanian pyrethrum fields. Plant Dis. 91:1116-1121.

14. Pethybridge, S. J., Esker, P. D., Hay, F. S., Wilson, C. R., and Nutter, F. W., Jr. 2005. Spatiotemporal description of epidemics caused by Phoma ligulicola in Tasmanian pyrethrum fields. Phytopathology 95:648-658.

15. Pethybridge, S. J., Gent, D. H., Esker, P. D., Turechek, W. W., Hay, F. S., and Nutter, F. W., Jr. 2009. Site-specific risk factors for ray blight in Tasmanian pyrethrum fields. Plant Dis. 93:229-237.

16. Pethybridge, S. J., Gent, D. H., and Hay, F. S. 2011. Epidemics of ray blight on pyrethrum are linked to seed contamination and overwintering inoculum of Phoma ligulicola var. inoxydabilis. Phytopathology 101:1112-1121.

17. Pethybridge, S. J., and Hay, F. S. 2001. Influence of Phoma ligulicola on yield and site factors on disease development in Tasmanian pyrethrum crops. Aust. Plant Pathol. 30:17-20.

18. Pethybridge, S. J., Hay, F. S., Esker, P. D., Gent, D. H., Wilson, C. R., and Nutter, F. W., Jr. 2008. Diseases of pyrethrum in Tasmania: challenges and prospects for management. Plant Dis. 92:1260-1272.

19. Pethybridge, S. J., Hay, F. S., Esker, P. D., Groom, T., Wilson, C. R., and Nutter, F. W., Jr. 2008. Visual and radiometric assessments for yield losses caused by ray blight in pyrethrum. Crop Sci. 48:343-352.

20. Pethybridge, S. J., Hay, F. S., and Groom, T. 2003. Seasonal fluctuations in fungi associated with pyrethrum foliage in Tasmania. Aust. Plant Pathol. 32:223-230.

21. Pethybridge, S. J., Hay, F. S., Groom, T., and Wilson, C. R. 2008. Improving fungicide-based management of ray blight disease in Tasmanian pyrethrum fields. Plant Dis. 92:887-895.

22. Pethybridge, S. J., Hay, F. S., Jones, S. J., Wilson, C. R., and Groom, T. 2006. Seedborne infection of pyrethrum by Phoma ligulicola. Plant Dis. 90:891-897.

23. Pethybridge, S. J., Hay, F. S., and Wilson, C. R. 2004. Pathogenicity of fungi commonly isolated from foliar disease in Tasmanian pyrethrum crops. Aust. Plant Pathol. 33:441-444.

24. Pethybridge, S. J., Hay, F. S., Wilson, C. R., and Groom, T. 2005. Development of a fungicide-based management strategy for foliar disease caused by 
Phoma ligulicola in Tasmanian pyrethrum fields. Plant Dis. 89:1114-1120.

25. Pethybridge, S. J., Scott, J. B., and Hay, F. S. 2012. Evidence against the Phoma ligulicola var. inoxydabilis population undergoing recombination or containing spatial structure in Australian pyrethrum fields. Plant Dis. 96:746-751.

26. Pethybridge, S. J., and Wilson, C. R. 1998. Confirmation of ray blight disease of pyrethrum in Australia. Aust. Plant Pathol. 27:45-48.

27. Pfender, W. F. 2001. A temperature-based model for latent-period duration in stem rust of perennial ryegrass and tall fescue. Phytopathology 91:111116.

28. Pruess, K. P. 1983. Day-degree methods for pest management. Environ. Entomol. 18:612-617.

29. Ring, D. R., Harris, M. K., Jackman, J. A., and Henson, J. L. 1983. A Fortran computer program for determining start date and base temperature for degree-day models. Texas Agric. Exp. Stn. Bull. MP-1537. The Texas
University System, College Station.

30. Scherm, H., and van Bruggen, A. H. C. 1994. Effects of fluctuating temperatures on the latent period of downy mildew (Bremia lactucae). Phytopathology 84:853-859.

31. Snyder, R. L., Spano, D., Cesaraccio, C., and Duce, P. 1999. Determining degree-day thresholds from field observations. Int. J. Biometeorol. 42:177182.

32. Vaghefi, N., Pethybridge, S. J., Ford, R., Nicolas, M. E., Crous, P. W., and Taylor, P. W. J. 2012. Stagonosporopsis spp. associated with ray blight disease of Asteraceae. Aust. Plant Pathol. 41:675-686.

33. Yang, S., Logan, J., and Coffey, D.L. 1995. Mathematical formulae for calculating the base temperature for growing degree-days. Agric. For. Meteorol. 74:61-74.

34. Zadoks, J. C., and Shein, R. D. 1979. Epidemiology and Plant Disease Management. Oxford University Press, Inc., New York. 